\title{
In-Depth Analysis of the Felder-Silverman Learning Style Dimensions
}

\author{
Sabine Graf \\ Vienna University of Technology, Austria \\ Silvia Rita Viola and Tommaso Leo \\ Universita' Politecnica delle Marche, Italy \\ Kinshuk \\ Athabasca University, Canada
}

\begin{abstract}
Learning styles are increasingly being incorporated into technology-enhanced learning. Appropriately, a great deal of recent research work is occurring in this area. As more information and details about learning styles becomes available, learning styles can be better accommodated and integrated into all aspects of educational technology. The aim of this paper is to analyse data about learning styles with respect to the Felder-Silverman learning style model (FSLSM) in order to provide a more detailed description of learning style dimensions. The analyses show the most representative characteristics of each learning style dimension as well as how representative these characteristics are. As a result, we provide additional information about the learning style dimensions of FSLSM. This information is especially important when learning styles are incorporated in technology-enhanced learning. (Keywords: learning styles, Felder-Silverman model, data mining, student modelling.)
\end{abstract}

\section{INTRODUCTION}

In recent years, educational researchers have focused more and more on various aspects of learning styles and how they can be considered in educational technology. Investigations about learning styles in technology-enhanced learning were conducted and several adaptive systems were developed that aim at incorporating learning styles and providing courses that fit to the individual learning styles of students. Examples of such systems include CS383 (Carver, Howard, \& Lane, 1999), IDEAL (Shang, Shi, \& Chen, 2001), MAS-PLANG (Peña, Marzo, \& de la Rosa, 2002), TANGOW (Paredes \& Rodríguez, 2004), and AHA! (Stash, Cristea, \& de Bra, 2006). The investigations about learning styles and the development of adaptive systems are motivated by learning style models which state that learners have different ways they prefer to learn. Incorporating learning styles in teaching plans may make learning easier and leads to better achievement. Furthermore, Felder, for example, pointed out that learners with a strong preference for a specific learning style may have difficulties if the teaching style does not match their preferred learning styles (Felder \& Silverman, 1988; Felder \& Soloman, 1997). Bajraktarevic, Hall, and Fullick (2003), for example, confirmed the benefits of providing adaptivity by a study showing that students attending an online course that matched with their 
preferred learning style (sequential or global) achieved significantly better results than those who took a course that did not match their preferred learning style.

A lot of research deals with learning styles in educational technology. For these investigations as well as for the development of adaptive systems, learning style models for traditional learning are often used. However, the majority of adaptive systems focusing on learning styles incorporate only some aspects of these traditional learning style models rather than all proposed characteristics of the model. This is motivated by the restriction of most adaptive systems to specific functions and a specific course structure (Brusilovsky, 2004). When conducting investigations about learning styles, it is therefore important to consider which characteristics of the learning style model are supported by the system.

In this paper, we focus on Felder-Silverman learning style model (FSLSM) (Felder \& Silverman, 1988), a learning style model that is often used in technology-enhanced learning and that is designed for traditional learning. The aim of this paper is to analyse data based on FSLSM to provide a more detailed description of its learning styles. Therefore, we aim at identifying characteristics of each of the four dimensions of FSLSM in order to be able to make a more gradual distinction within the learning style dimensions. Furthermore, we analyse how representative each characteristic is for each learning style dimension.

Such detailed information is beneficial in many ways. In general, a more detailed description of learning styles improves student modelling and as such leads to a more accurate model of the student. This again helps to provide more suitable adaptivity while allowing more detailed research about learning styles.

For example, if an online environment supports a learning style only partially, this has to be considered when analysing the output of the system and drawing conclusions. When using information about learning styles to provide adaptivity, a detailed description of learning styles can improve the adaptation process. If a system supports only some characteristics of a learning style, then a student model that includes information about exactly these characteristics is needed to provide suitable adaptivity rather then using information about the overall learning style.

Another example for the use of such detailed information about learning styles is the derivation of learning styles from the behaviour of students during an online course. While such an approach has been recently investigated for different systems (Cha et al., 2006; García, Amandi, Schiaffino, \& Campo, in press; Graf \& Kinshuk, 2006), it should also be noted that not all characteristic behaviour described in the learning style model can be mapped as well as identified from the behaviour in a specific learning system. Thus, the patterns which indicate specific preferences for learning styles are adapted to the features of the systems. When identifying the learning style, it is therefore important to know which characteristics can be mapped and identified, and which cannot. Being aware of the characteristics and their relevance for the learning style leads to a better estimation of the results of the approach and hence, to a more meaningful application of the identified information. 
Detailed information about learning styles is also crucial when identifying relationships between learning styles and the performance of students in an online course (see Hayes \& Allinson, 1996) or other characteristics of students such as cognitive traits (Graf, Lin, \& Kinshuk, in press). A detailed description of the different characteristics of each dimension and how representative they are for that specific dimension of the learning style is necessary. FSLSM provides a framework that is suitable for this kind of analysis.

After introducing FSLSM, we focus on describing the Index of Learning Styles (ILS) questionnaire (Felder \& Soloman, 1997), which was used for data collection, and discuss the results of the conducted analyses. We used linear discriminant analysis in order to detect the most representative characteristics of learning styles as represented in the gathered data. Furthermore, we analysed how representative these characteristics are for the specific learning style dimensions. For cross-validation, we conducted empirical frequencies analysis as well as correlation analysis. We conclude with recommendations for further research.

\section{Felder-Silverman Learning Style Model (FSLSM)}

There are several different learning style models including Kolb (1984), Honey and Mumford (1982), and Felder and Silverman (1988). Each proposes different descriptions and classifications of learning styles. In our work, we are focusing on the Felder-Silverman learning style model (FSLSM). Most other learning style models classify learners into a few groups, whereas Felder and Silverman describe the learning style of a learner in more detail, distinguishing between preferences on four dimensions. Another main difference is that FSLSM is based on tendencies, indicating that learners with a high preference for certain behaviour can also act sometimes differently.

FSLSM is used very often in research related to learning styles in advanced learning technologies. According to Carver et al. (1999), "the Felder Model is most appropriate for hypermedia courseware" (p. 34). Kuljis and Liu (2005) confirmed this by conducting a comparison of learning style models with respect to the application in e-learning and Web-based learning systems. As a result, they also suggest FSLSM as the most appropriate model.

There are four dimensions in FSLSM. Each learner is characterized by a specific preference for each of these dimensions. The first dimension distinguishes between an active and a reflective way of processing information. Active learners learn best by working actively with the learning material, by applying the material, and by trying things out. Furthermore, they tend to be more interested in communication with others and prefer to learn by working in groups where they can discuss about the learned material. In contrast, reflective learners prefer to think about and reflect on the material. Regarding communication, they prefer to work alone or maybe in a small group together with one good friend.

The second dimension covers sensing versus intuitive learning. Learners who prefer a sensing learning style like to learn facts and concrete learning material. They like to solve problems with standard approaches and also tend to be more patient with details. Furthermore, sensing learners are considered to be more 
realistic and sensible; they tend to be more practical than intuitive learners and like to relate the learned material to the real world. In contrast, intuitive learners prefer to learn abstract learning material, such as theories and their underlying meanings. They are more able to discover possibilities and relationships and tend to be more innovative and creative than sensing learners.

The third, visual-verbal dimension differentiates learners who remember best and therefore prefer to learn from what they have seen (e.g., pictures, diagrams and flow-charts), and learners who get more out of textual representations, regardless of whether they are written or spoken.

In the fourth dimension, the learners are characterized according to their understanding. Sequential learners learn in small incremental steps and therefore have a linear learning progress. They tend to follow logical stepwise paths in finding solutions. In contrast, global learners use a holistic thinking process and learn in large leaps. They tend to absorb learning material almost randomly without seeing connections but after they have learned enough material they suddenly get the whole picture. Then they are able to solve complex problems, find connections between different areas, and put things together in novel ways but they have difficulties in explaining how they did it. Because the whole picture is important for global learners, they tend to be more interested in overviews and in a broad knowledge whereas sequential learners are more interested in details.

\section{Data Collection and Data Analyses}

In order to investigate the learning style of students we performed a study where 207 students participated. One hundred and twenty-two students were from Massey University in New Zealand and 85 from Vienna University of Technology in Austria. The mixed group of students, from bachelor to $\mathrm{PhD}$ level, was recruited from particular courses such as Web Engineering and Information Management, and mostly studied Information Systems. To detect the learning styles of the students, they completed a questionnaire developed by Felder and Soloman (1997). In the following section, this questionnaire is briefly introduced and afterwards the results of our study are presented.

\section{Index of Learning Styles}

The Index of Learning Styles (ILS), developed by Felder and Soloman, is a 44-item questionnaire for identifying the learning styles according to FSLSM. As mentioned earlier, each learner has a personal preference for each dimension. These preferences are expressed with values between +11 to -11 per dimension, with steps $+/-2$. This range comes from the 11 questions that are posed for each dimension. When answering a question, for instance, with an active preference, +1 is added to the value of the active/reflective dimension whereas an answer for a reflective preference decreases the value by 1 . Therefore, each question is answered either with a value of $+1($ answer $a)$ or -1 (answer $b$ ). Answer $a$ corresponds to the preference for the first pole of each dimension (active, sensing, visual, or sequential), answer $b$ to the second pole of each dimension (reflective, intuitive, verbal, or global). 
The ILS is an often used and well-investigated instrument to identify learning styles. Felder and Spurlin (2005) provided an overview of studies dealing with analysing the response data of ILS regarding the distribution of preferences for each dimension as well as with verifying the reliability and validity of the instrument. While these studies seem to support the argument that ILS is reliable, valid and suitable, open issues arose such as dependencies between some learning styles and the existence of some latent dimensions which need further investigations (e.g., Viola, Graf, Kinshuk, \& Leo, 2007).

\section{General Analysis}

First, we analyzed the distribution of preferences for each dimension. As a result, $57 \%$ of the students in our study were found to have an active preference, $58 \%$ a sensing preference, $87 \%$ a visual preference, and $56 \%$ a global preference. Table 1 shows a more detailed description, classifying the preferences of learners in strong/moderated (values from 5 to 11 in the ILS) and balanced (values from +3 to -3 in the ILS). Looking at the overview of similar studies given by Felder and Spurlin (2005), our results are mainly in agreement with the results of these studies. Some small differences can be seen in the sensing/ intuitive dimension, where slightly more intuitive learners have attended our study, as well as in the sequential/global dimension where more global learners have participated.

According to the distribution of the preferences, it can be seen that the results of our study are in agreement with the results of studies already performed.

\section{Grouping of Questions}

Looking at FSLSM, it can be seen that each learning style is described by different characteristics. Based on the description of FSLSM (Felder \& Silverman, 1988), the questions in ILS were manually grouped according to the similarity of semantics. Table 2 provides the semantic groups identified for each learning style as well as the questions belonging to these groups. A question may appear twice in the table, if the answer to the question points to two different semantic groups.

\section{Analyses of Semantic Groups}

According to the classification provided in Table 2, some analyses were performed in order to detect the most representative groups for each learning style. The analyses were performed based on the data from the ILS questionnaire.

In order to find the most representative semantic groups of each dimension, Fisher linear discriminant analysis (e.g., Duda, Hart, \& Stork, 2000), a well known multivariate method for linear optimal separating dimensionality reduction, was conducted. Then the model given by linear discriminant analysis was compared with some empirical results regarding both frequencies analysis and correlation analysis in order to cross-validate it.

Detecting Characteristics of the Learning Style Dimensions. In order to apply consistently statistical methods, data were transformed in frequencies, i.e. on absolute scale, as follows. Let $Q$ be the $207 \times 44$ matrix containing in rows individuals and in column the answer to each ILS question. For each question $q_{i}$, 

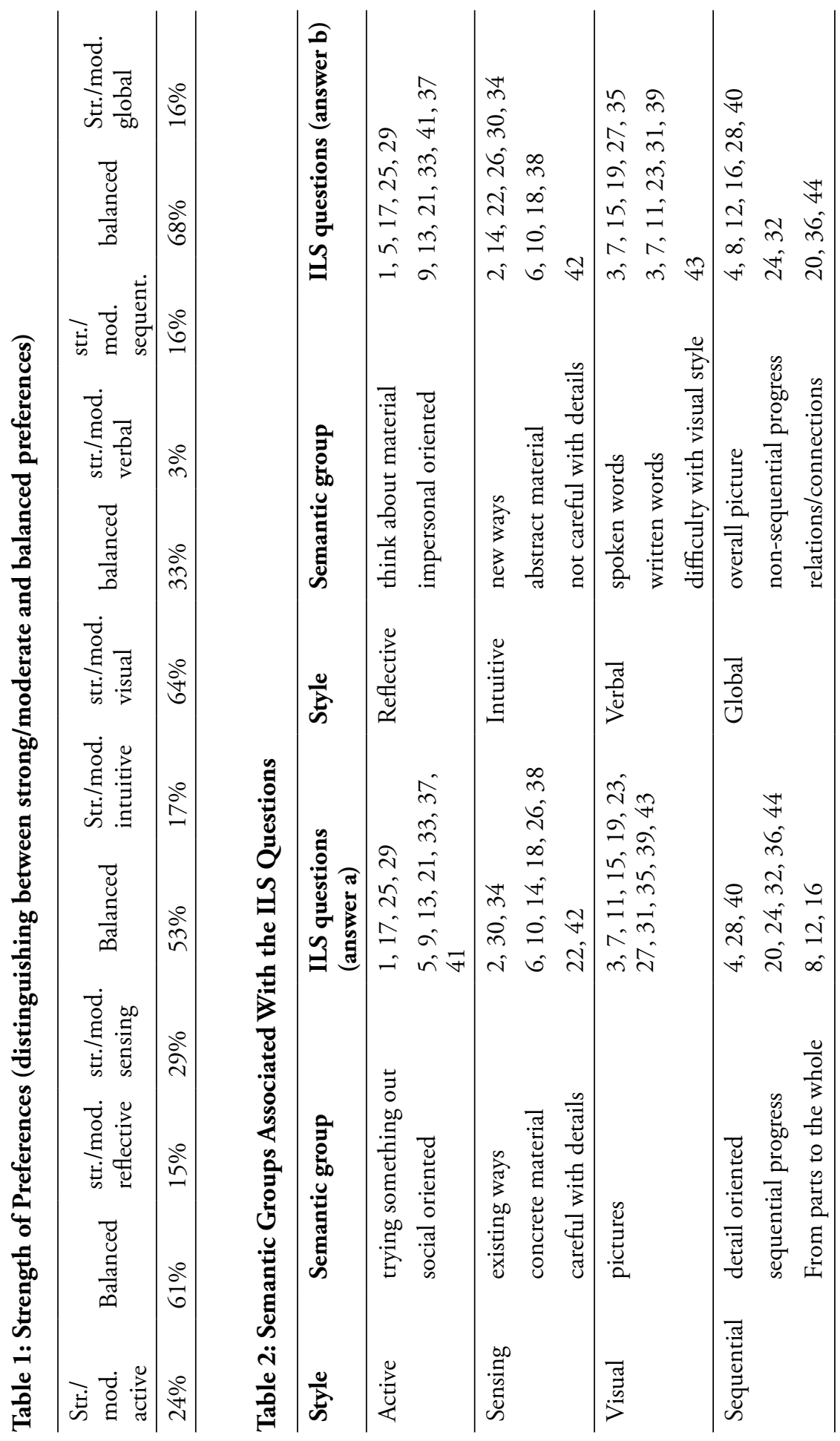
$Q=44$, two numerical variables, namely the two answers to each questions, $a_{1}=$ 1 if $q_{i}=1$ (otherwise 0) and $a_{2}=1$ if $q_{i}=-1$ (otherwise 0) were obtained.

Let $A$ be the $207 \times 88$ matrix containing in rows individuals and in columns the $a_{i}, \mathrm{i}=1, \ldots, 88$. The matrix $A$ has rank at most 44 by construction, since two columns are constrained to sum up to 1 in rows. Fisher linear discriminant analysis (LDA) was then performed on the whole matrix $A$ of learners' answers to ILS.

This method, a well known multivariate method for dimensionality reduction, is able to find the optimal linear direction of separation. This direction is given by a vector of coefficients $w$, usually one-dimensional, that maximize the inter-class separation. Within this vector, the highest absolute values of coefficients indicate the most important variables for discrimination. In this study, LDA was used to find the most important ILS questions for discriminating between each FSLSM dimension (that is, active/reflective, sensing/intuitive, visual/verbal, sequential/global) according to the answers given by the learners.

More formally, being X an $m$-by- $n$ matrix, let $w^{\prime} m_{i}^{(1)}$ and $w^{\prime} m_{i}^{(2)}, i=1, \ldots, n$, be the $d$-dimensional sample means of the projected points according to the classes of individuals, and $(1 / \mathrm{m})\left(s 1^{2}+s 2^{2}\right)$ an estimate of the whole variance of the pooled data, where

$$
s c^{2}=\sum_{x \in C_{i}} w^{\prime} x_{i}-w^{\prime} m_{i}^{(c)}
$$

and $c \in C=\{1, \ldots, k\}$ indicates the class; LDA is aimed at finding a vector $w$ that maximizes the criterion function

$$
J(w)=\frac{\left|w^{\prime} m_{i}^{(1)}-w^{\prime} m_{i}^{(2)}\right|^{2}}{s 1^{2}+s 2^{2}}
$$

The outcome of the method is a new geometrical representation that maximizes the separation between two sets of points obtained by a projection on a lower dimensional space (usually 1-dimensional). In the vector of coefficients $w$, that in this case has dimensions $(88,1)$ weights associated to each variable are arranged according to the contribution in separating the sets along the direction given by $w$. For all the four couples of styles both the relative direction and the coefficients were detected.

Due to the rank deficiency and to the redundancy of the matrix $A$, the outcome of LDA showed a vector in which the coefficients associated with each answer were equal in absolute values, but opposite in signs according to the association with each style inside each of the four ILS dimensions.

In order to detect the importance of each semantic group within the learning style dimensions, the coefficients of $w$ associated with each answer were investigated using a synthetic index of the importance of each semantic group of questions according to each learning style dimension, calculated as the average of the absolute values of the coefficients related to each answer in Table 2. Table 3 summarizes the results. 
Table 3: The Relevance of the Semantic Groups on the Learning Style Dimensions (values $>0.5$ are highlighted)

\begin{tabular}{|c|c|c|c|c|c|}
\hline Styles & Semantic groups & Act/ Ref & Sen/Int & Vis/Ver & Seq/Glo \\
\hline \multirow[t]{2}{*}{ Active } & try something out & 0.639 & 0.113 & 0.536 & 0.211 \\
\hline & social oriented & 0.452 & 0.146 & 0.190 & 0.180 \\
\hline \multirow[t]{2}{*}{ Reflective } & think about material & 0.597 & 0.122 & 0.486 & 0.217 \\
\hline & impersonal oriented & 0.698 & 0.143 & 0.175 & 0.170 \\
\hline \multirow[t]{3}{*}{ Sensing } & existing ways & 0.237 & 0.568 & 0.301 & 0.174 \\
\hline & concrete materials & 0.178 & 0.777 & 0.380 & 0.245 \\
\hline & careful with details & 0.147 & 0.409 & 0.329 & 0.456 \\
\hline \multirow[t]{3}{*}{ Intuitive } & new ways & 0.193 & 0.678 & 0.309 & 0.237 \\
\hline & abstract material & 0.225 & 0.715 & 0.453 & 0.173 \\
\hline & not careful with details & 0.008 & 0.699 & 0.026 & 0.151 \\
\hline Visual & pictures & 0.238 & 0.227 & 0.944 & 0.167 \\
\hline \multirow[t]{3}{*}{ Verbal } & spoken words & 0.202 & 0.189 & 0.648 & 0.171 \\
\hline & written words & 0.171 & 0.199 & 1.086 & 0.258 \\
\hline & difficulty with visual style & 0.297 & 0.388 & 0.789 & 0.078 \\
\hline \multirow[t]{3}{*}{ Sequential } & detail oriented & 0.224 & 0.218 & 0.290 & 0.800 \\
\hline & sequential progress & 0.100 & 0.237 & 0.432 & 0.686 \\
\hline & from parts to the whole & 0.123 & 0.154 & 0.113 & 0.839 \\
\hline \multirow[t]{3}{*}{ Global } & overall picture & 0.174 & 0.186 & 0.202 & 0.819 \\
\hline & non-sequential progress & 0.140 & 0.175 & 0.520 & 0.715 \\
\hline & relations/connections & 0.074 & 0.278 & 0.375 & 0.869 \\
\hline
\end{tabular}

Since a high value indicates a strong impact of the semantic group for the respective learning style, it can be seen that for an active learning style the preference for trying something out has more impact than the preference for social orientation (e.g., for discussing and explaining learning material to each other or working in groups). On the other hand, for a reflective learning style, the social behaviour is more relevant than the preference to think/reflect about learning material. That means that for supporting students with a reflective learning style, it is important to give them the opportunity to work individually.

Regarding the sensing/intuitive dimension it can be seen that the preference for concrete learning material seems to be most important for learners with a sensing learning style. The preference for abstract material is most relevant for intuitive learners. While for sensing learners, the carefulness with details seems to be less representative, the tendency for being not patient and not careful with details is characteristic for intuitive learners.

For the visual learning style, only one semantic group exists, which is also highly representative. For the verbal learning style, the most representative se- 
mantic group is the preference for written words. But also spoken words and the difficulty with visual style seems to play a relevant role. It is interesting to note that the results of the visual/verbal dimension show additionally an impact regarding the preference of trying something out and a non-sequential learning progress. Since these relations are not described in FSLSM, further investigations are necessary.

Regarding the sequential/global dimension, all six semantic groups of the dimension show high relevance for the respective learning styles. Most important is the preference for relations and connections to other areas for global learners, while for sequential learners the ability to infer from parts to the whole solution is most relevant. The groups for a sequential or non-sequential way of learning achieved for both learning styles the lowest value, but are still representative.

Cross Validation. In order to cross-validate results, both Pearson's correlations and empirical frequencies were used. In the empirical frequencies analysis, we compare how often students with a particular learning style answer a question with a specific preference. Considering the active/reflective dimension as an example, a question is representative, if students with an active learning style answer this question clearly more often with an active preference than student with a reflective learning style. To prove that questions for the active/reflective dimension are representative, the percentage of active learners, answering a question with an active preference, is compared with the percentage of reflective learners, answering the question with an active preference. The difference of these percentage values acts as a measure indicating how representative a question is for the active/reflective dimension. Accordingly, measures for all other dimensions were calculated. Seven questions of the active/reflective dimension, 10 of the sensing/intuitive dimension, nine of the visual/verbal dimension, and five of the sequential/global dimension achieved a difference of $30 \%$ or more. All these questions except one belong to the respective dimension. The one exception indicated a sequential/global learning style but seems to be representative for the sensing/intuitive dimension as well as for the sequential/global dimension. This can be explained by the existing correlation between the sensing/intuitive and sequential/global dimension (reported in Felder \& Spurlin, 2005, as well as identified by the performed correlation analysis). Overall, this analysis shows that almost all of the questions are highly representative for their dimensions.

In order to identify the most representative questions for each dimension, the questions were ranked according to the above introduced criterion. The five most representative questions for each dimension are shown in Table 4.

Regarding the active/reflective dimension, it can be seen that the first, third, and fifth ranked questions deal with social oriented behaviour asking whether students are considered as outgoing, gotten to know many other students in a class, and liked to work in groups. In contrast, the second and fourth ranked questions are about whether students tend to try things out or think the learned material through. These two characteristics were identified in the previous section as well. As a result of both analyses, it can be seen that social behaviour as well as the preference for trying things out or thinking things through are im- 
Table 4: The Five Most Representative Questions for Each Dimension of the ILS According to Frequencies Analysis

\begin{tabular}{|c|c|c|c|}
\hline & Rank & $\begin{array}{l}\text { Question } \\
\text { No. }\end{array}$ & Question \\
\hline \multirow{5}{*}{ 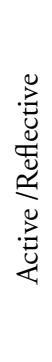 } & 1 & 37 & I am more likely to be considered (a) outgoing. (b) reserved. \\
\hline & 2 & 1 & $\begin{array}{l}\text { I understand something better after I (a) try it out. (b) think it } \\
\text { through. }\end{array}$ \\
\hline & 3 & 13 & $\begin{array}{l}\text { In classes I have taken (a) I have usually gotten to know many of the } \\
\text { students. (b) I have rarely gotten to know many of the students. }\end{array}$ \\
\hline & 4 & 25 & $\begin{array}{l}\text { I would rather first (a) try things out. (b) think about how I'm going } \\
\text { to do it. }\end{array}$ \\
\hline & 5 & 21 & I prefer to study (a) in a study group. (b) alone. \\
\hline \multirow{5}{*}{ } & 1 & 6 & $\begin{array}{l}\text { If I were a teacher, I would rather teach a course (a) that deals with } \\
\text { facts and real life situations. (b) that deals with ideas and theories. }\end{array}$ \\
\hline & 2 & 38 & $\begin{array}{l}\text { I prefer courses that emphasize (a) concrete material (facts, data). (b) } \\
\text { abstract material (concepts, theories). }\end{array}$ \\
\hline & 3 & 18 & I prefer the idea of (a) certainty. (b) theory. \\
\hline & 4 & 10 & I find it easier (a) to learn facts. (b) to learn concepts. \\
\hline & 5 & 2 & I would rather be considered (a) realistic. (b) innovative. \\
\hline \multirow{5}{*}{ 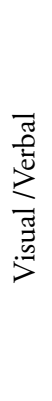 } & 1 & 31 & $\begin{array}{l}\text { When someone is showing me data, I prefer (a) charts or graphs. (b) } \\
\text { text summarizing the results. }\end{array}$ \\
\hline & 2 & 11 & $\begin{array}{l}\text { In a book with lots of pictures and charts, I am likely to (a) look } \\
\text { over the pictures and charts carefully. (b) focus on the written text. }\end{array}$ \\
\hline & 3 & 7 & $\begin{array}{l}\text { I prefer to get new information in (a) pictures, diagrams, graphs, or } \\
\text { maps. (b) written directions or verbal information. }\end{array}$ \\
\hline & 4 & 19 & I remember best (a) what I see. (b) what I hear. \\
\hline & 5 & 3 & $\begin{array}{l}\text { When I think about what I did yesterday, I am most likely to get (a) } \\
\text { a picture. (b) words. }\end{array}$ \\
\hline \multirow{5}{*}{ 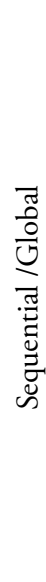 } & 1 & 36 & $\begin{array}{l}\text { When I am learning a new subject, I prefer to (a) stay focused on } \\
\text { that subject, learning as much about it as I can. (b) try to make con- } \\
\text { nections between that subject and related subjects. }\end{array}$ \\
\hline & 2 & 20 & $\begin{array}{l}\text { It is more important to me that an instructor (a) lay out the material } \\
\text { in clear sequential steps. (b) give me an overall picture and relate the } \\
\text { material to other subjects. }\end{array}$ \\
\hline & 3 & 8 & $\begin{array}{l}\text { Once I understand (a) all the parts, I understand the whole thing. } \\
\text { (b) the whole thing, I see how the parts fit. }\end{array}$ \\
\hline & & 44 & $\begin{array}{l}\text { When solving problems in a group, I would be more likely to (a) } \\
\text { think of the steps in the solution process. (b) think of possible con- } \\
\text { sequences or applications of the solution in a wide range of areas. }\end{array}$ \\
\hline & 5 & 4 & $\begin{array}{l}\text { I tend to (a) understand details of a subject but may be fuzzy about } \\
\text { its overall structure. (b) understand the overall structure but may be } \\
\text { fuzzy about details. }\end{array}$ \\
\hline
\end{tabular}


portant for the active/reflective dimension. Since discriminant analysis is more accurate for distinguish relevant aspects, the outcomes provided by it underline better the difference of the impact of social behaviour for active learners and reflective learners.

In the sensing/intuitive dimension it can be seen clearly that the first four questions are dealing with the preference for concrete material like facts and data or abstract material such as concepts and theories. Therefore this characteristic seems to be the most representative one for this dimension. This is also confirmed by the results of the discriminant analysis. The fifth question is about whether a student considers himself/herself as realistic or innovative and belongs to the semantic group of existing ways/new ways, which can be seen as the second important characteristic according to discriminant analysis.

Regarding the visual/verbal dimension, it is interesting to see that the first two questions from the verbal point of view are about written text, question three and five consider written and spoken words and only the fourth question is about spoken words. While there are more questions about written words than about spoken ones, the results nevertheless indicates that for verbal learners both, written and spoken language are important. For visual learners, there is only one characteristic namely to learn best from what they see. These results are in agreement with the results from the discriminant analysis.

In the sequential/global dimension, the first, second, and fourth questions deal with whether students prefer a sequential way of learning (from the viewpoint of a sequential style) or whether relationships and connections to other areas are more important for them (from the viewpoint of a global style). The other questions are about the other two semantic groups respectively for a sequential and global learning style. According to the results from discriminant analysis, all relevant semantic groups are covered by the five most relevant questions from Table 4. While for the global style the order of relevance is in agreement of both analyses, for the sequential style the preference for a sequential learning progress seems to be less relevant according the discriminant analysis.

Looking at correlations inside frequencies of the answers according to each of the eight learning styles, interesting features emerged. Correlations were calculated over the total number of positive answers to each of the 88 answers allowed by ILS ( 2 possible answers for each question), transforming then data from a binary scale to an equivalent numeral one, for coherence and consistency with the applications of Pearson's correlation coefficients and related $\mathrm{p}$ values.

Many high (greater than 0.7 ) values were found; related $\mathrm{p}$ values were very small $(\mathrm{p}<0.05)$, indicating a significance. In particular, a great number of high absolute values of correlation coefficients involve questions belonging to all semantic groups associated with the active/reflective dimension and cross dimension correlations between these groups; questions belonging to all semantic groups associated with the sequential/global dimension and cross correlation questions between these groups, and questions belonging to the semantic groups associated with the visual/verbal dimension (pictures/spoken and written words). 
Some considerations can be made on these results. The difference of empirical frequencies present at the first positions of rank variables that in most cases achieve high correlations, and for this reason some semantic groups are not represented. LDA seems instead to be more able to include all the representative characteristics. Moreover, it seems able to give a more accurate indication about the importance of each characteristic.

Eventually, it looks like, looking at the results, that some correlations between dimensions of learning styles are likely. This hypothesis needs a deeper and dedicated investigation both of the analyses presented by literature (Felder $\&$ Spurlin, 2005) and the statistical analyses performed on this dataset in order to be tested and explained.

\section{Conclusion and Future Work}

In this paper, we provided an in-depth analysis of data from the ILS questionnaire with the aim to get a more detailed description of the learning style dimensions of Felder-Silverman learning style model (FSLSM). Therefore, we divided each learning style dimension in semantic groups (such as the preference for spoken language or the preference for concrete learning material), and analysed the impact of each group for each learning style. A hybrid approach was used for detecting interesting features both from research and from application viewpoint.

The results showed a more accurate description of FSLSM, pointing out relevant characteristics within the dimensions. Especially for the use of learning styles in technology-enhanced learning, such an accurate description is important for relating the learning style model with the features of the online environment. In recent years, technology-enhanced learning has put great attention on learning styles in order to improve adaptivity in technology-enhanced educational systems. Incorporating not only learning style dimensions but also the different characteristics within these dimensions lead to a more accurate representation of students' learning styles and therefore enhance the potentials of adaptive learning environments. Moreover, the in-depth investigation of learning style characteristics could improve also pedagogical models, supporting a more effective and personalized learning.

Future work will include additional statistical analyses in order to confirm our results. An extension of the results of the ILS questionnaire might be a meaningful aim for future work as well, in order to provide not only information about the learning style dimension but also about their semantic groups. Furthermore, we plan to use the additional information of semantic groups for improving student modelling and use this additional data in the student model to provide more suitable adaptivity. Another area of application and future research work will deal with incorporating the detailed description of learning styles to detect learning styles automatically from the behaviour of students in online courses. Moreover, the more detailed information can help to investigate relationships between learning styles and, for instance, performance or characteristics of students such as cognitive traits. 


\section{ACKNOWLEDGEMENTS}

This research is curiosity driven and has been funded partly by the Austrian Federal Ministry for Education, Science, and Culture, and the European Social Fund (ESF) under grant 31.963/46-VII/9/2002.

\section{Contributors}

Sabine Graf is Graduate Researcher at Vienna University of Technology, Women's Postgraduate College for Internet Technologies, in Austria. She is also researcher at Advanced Learning Technology Research Centre of Massey University, New Zealand. Her research interests include adaptivity in Webbased educational systems, student modelling, and artificial intelligence. (Address: Vienna University of Technology, Women's Postgraduate College for Internet Technologies, Favoritenstrasse 9-11, E188/4, Vienna, Austria; phone: 431.58801.18817; fax: 431.58801.18895; sabine.graf@ieee.org)

Silvia Rita Viola was born in 1976. In 2001 she graduated with a degree in philosophy at the University of Pisa. On February, 2006, she earned a PhD in e-learning at the Universita' Politecnica delle Marche, Ancona, Italy. Her research interests are in mathematical models of World Wide Web data, learning process characterization by data driven approaches and mathematical bioengineering modelling. She is currently with the Universita' Politecnica delle Marche as a research associate and with the University for Foreigners in Italy, as lecturer for the course titled Knowledge Engineering. (Address: Dipartimento di Ingegneria Informatica, Gestionale e dell' Automazione "Maurizio Panti," Univerista' Politecnica delle Marche, Via delle Brecce Bianche, 60100 Ancona, Italy; phone: 39071 2204842; fax: 39071 2204474; sr.viola@gmail.com)

Kinshuk joined Athabasca University in August 2006 as the professor and director of the School of Computing and Information Systems. Before moving to Canada, Kinshuk worked at the German National Research Centre for Information Technology as a postgraduate fellow, and at Massey University, New Zealand, as an associate professor of Information Systems and director of the Advanced Learning Technology Research Centre. He also holds the Honorary Senior E-Learning Consultant position with Online Learning Systems Ltd., New Zealand, and the Docent position with the University of Joensuu, Finland. He has been involved in large-scale research projects for exploration based adaptive educational environments and has published extensively in international refereed journals, conferences, and book chapters. He is chair of the IEEE Technical Committee on Learning Technology and International Forum of Educational Technology \& Society. He is also editor of the SSCI indexed Journal of Educational Technology \& Society (ISSN 14364522). (Address: School of Computing and Information Systems, Athabasca University, 1 University Drive, Athabasca, AB T9S 3A3, Canada; phone: 1.780.675.6812; fax: 1.780.675.6148; kinshuk@ieee.org)

Tommaso Leo, born in 1944, is full professor at the Chair of Automatic Control-Ancona University since 1981 . He is author and co-author of more than 200 papers, editor of some books and special issues in journals. He is a member of several scientific societies. He has been involved in several national 
and international research funded programs. His research interests are in analysis and modelling of human motor behaviour, measurement systems and techniques, signal processing and optimal filtering, adaptive control and system identification, friendly interfaces in biomedicine, Web-based applications for learning and accreditation, and in assistive robotics. (Address: Dipartimento di Ingegneria Informatica, Gestionale e dell' Automazione, Univerista' Politecnica delle Marche, Via delle Brecce Bianche, 60100 Ancona, Italy; phone: 39071 2204842; fax: 39071 2204474; tommaso.leo@univpm.it)

\section{References}

Bajraktarevic, N., Hall, W., \& Fullick, P. (2003). Incorporating learning styles in hypermedia environment: Empirical evaluation. In P. de Bra, H. C. Davis, J. Kay \& M. Schraefel (Eds.), Proceedings of the Workshop on Adaptive Hypermedia and Adaptive Web-Based Systems (pp. 41-52). Nottingham, UK.

Brusilovsky, P. (2004). Knowledge Tree: A distributed architecture for adaptive e-learning. In S. I. Feldman, M. Uretsky, M. Najork, \& C. E. Wills (Eds.), Proceedings of the International Conference on World Wide Web (pp. 104-113). New York: ACM Press.

Carver, C. A., Howard, R. A., \& Lane, W. D. (1999). Addressing different learning styles through course hypermedia. IEEE Transactions on Education, 42(1), 33-38.

Cha, H. J., Kim, Y. S., Park, S. H., Yoon, T. B., Jung, Y. M., \& Lee, J. H. (2006). Learning style diagnosis based on user interface behaviour for the customization of learning interfaces in an intelligent tutoring system. In M. Ikeda, K. D. Ashley \& T.-W. Chan (Eds.), Proceedings of the 8th International Conference on Intelligent Tutoring Systems, Lecture Notes in Computer Science (Vol. 4053, pp. 513-524). Berlin, Heidelberg: Springer-Verlag.

Duda, R. O., Hart, P. E., \& Stork, D. G. (2000). Pattern classification (2 ed.). New York: Wiley.

Felder, R. M., \& Silverman, L. K. (1988). Learning and teaching styles in engineering education. Engineering Education, 78(7), 674-681. Preceded by a preface in 2002: http://www.ncsu.edu/felderpublic/ Papers/LS-1988.pdf

Felder, R. M., \& Soloman, B. A. (1997). Index of Learning Styles questionnaire. Retrieved 30 April, 2006, from http://www.engr.ncsu.edu/learningstyles/ ilsweb.html

Felder, R. M., \& Spurlin, J. (2005). Applications, reliability and validity of the Index of Learning Styles. International Journal on Engineering Education, 21(1), 103-112.

García, P., Amandi, A., Schiaffino, S., \& Campo, M. (in press). Evaluating Bayesian networks' precision for detecting students' learning styles. Computers \& Education.

Graf, S., \& Kinshuk. (2006). An approach for detecting learning styles in learning management systems. In Kinshuk, R. Koper, P. Kommers, P. Kirschner, D. G. Sampson \& W. Didderen (Eds.), Proceedings of the International Conference on Advanced Learning Technologies (pp. 161-163). Alamitos, CA: IEEE Computer Science. 
Graf, S., Lin, T., \& Kinshuk. (in press). The relationship between learning styles and cognitive traits - getting additional information for improving student modelling. International Journal on Computers in Human Behavior.

Hayes, J., \& Allinson, C. W. (1996). The implications of learning styles for training and development: A discussion of the matching hypothesis. British Journal of Management, 7, 63-73.

Honey, P., \& Mumford, A. (1982). The manual of learning styles. Maidenhead: Peter Honey.

Kolb, D. A. (1984). Experiential learning: Experience as the source of learning and development. Englewood Cliffs, New Jersey: Prentice-Hall.

Kuljis, J. \& Liu, F. (2005). A comparison of learning style theories on the suitability for elearning. In M. H. Hamza (Ed.), Proceedings of the IASTED Conference on Web-Technologies, Applications, and Services (pp. 191-197). ACTA Press.

Paredes, P., \& Rodríguez, P. (2004). A mixed approach to modelling learning styles in adaptive educational hypermedia. Advanced Technology for Learning, 1(4), 210-215.

Peña, C. I., Marzo, J. L., \& de la Rosa, J. L. (2002). Intelligent agents in a teaching and learning environment on the web. In V. Petrushin, P. Kommers, Kinshuk \& I. Galeev (Eds.), Proceedings of the International Conference on Advanced Learning Technologies (pp. 21-27). Palmerston North, NZ: IEEE Learning Technology Task Force.

Shang, Y., Shi, H., \& Chen, S. S. (2001). An intelligent distributed environment for active learning. ACM Journal of Educational Resources in Computing, 1(2), 1-17.

Stash, N., Cristea, A., \& de Bra, P. (2006). Adaptation to learning styles in elearning: Approach evaluation. In T. Reeves \& S. Yamashita (Eds.), Proceedings of World Conference on E-Learning in Corporate, Government, Healthcare, and Higher Education (pp. 284-291). Chesapeake, VA: AACE.

Viola, S. R., Graf, S., Kinshuk, \& Leo, T. (2007). Investigating relationships within the Index of Learning Styles: A data-driven approach. International Journal of Interactive Technology and Smart Education, 4(1), 7-18. 